\title{
Diyarbakır ili pamuk ekim alanlarında bulunan yeşilkurt, Helicoverpa armigera (Hübner) (Lepidoptera: Noctuidae)'un popülasyon dalgalanmasının belirlenmesi
}

\author{
Determination of population fluctuation of American bollworm, Helicoverpa armigera \\ (Hübner) (Lepidoptera: Noctuidae) on cotton fields in Diyarbakır, Turkey
}

\author{
Merve AKYILDIZ ${ }^{1}$ iD, Erol BAYHAN ${ }^{2 *}$ iD \\ ${ }^{1}$ Diyarbakır Zirai Mücadele ve Araştırma Enstitüsü Müdürlüğü, DiYARBAKIR \\ ${ }^{2}$ Dicle Üniversitesi, Ziraat Fakültesi, Bitki Koruma Bölümü, Sur-DiYARBAKIR
}

\section{To cite this article:}

Akyıldız, M., Bayhan, E., 2018. Diyarbakır ili pamuk ekim alanlarında bulunan yeşilkurt, Helicoverpa armigera (Hübner) (Lepidoptera: Noctuidae)'un popülasyon dalgalanmasının belirlenmesi. Harran Tarim ve Gida Bilimleri Dergisi, 22(2): 186-195

Address for Correspondence: Erol BAYHAN

e-mail:

erolbayhan@gmail.com

\section{Received Date:}

11.12.2017

Accepted Date:

17.04.2018

(c) Copyright 2018 by Harran University Faculty of Agriculture. Available on-line at www.dergipark.gov.tr/harranziraat

\section{öz}

Pamuğun en önemli zararlılarından biri olan Yeşilkurt, Helicoverpa armigera Hübner (Lepidoptera: Noctuidae) özellikle jeneratif organlarda zarar yaparak önemli ürün kayıplarına neden olmaktadır. Bu çalışma $H$. armigera'nın ergin popülasyon değişimini saptamak amacıyla Delta tipi eşeysel çekici tuzakların yerleştirildiği pamuk tarlalarında 2014 ve 2015 yıllarında Diyarbakır iline bağı üç ilçede yürütülmüştür. Bismil (Kazancı), Çınar (Karalar), Sur (Tanoğlu) ilçelerinde üç pamuk tarlası belirlenmiş ve her tarlaya üçer adet feromon tuzakları yerleştirilmiştir. Tuzaklarda yakalanan erginler haftalık yapılan sayımlarla takip edilmiştir. Çalışmalardan elde edilen verilere göre $H$. armigera'nın popülasyon dalgalanması 2014 ve 2015 yıllarında genel olarak aylara ve yıllara göre farklılık göstermiştir. Denemelerin yürütüldüğü tarlalarda 2014 yılında yapılan sayımlarda tuzaklarda daha fazla kelebek yakalanırken, 2015 yılında daha düşük sayıda kelebek yakalanmıştır. Yeşilkurt ergin popülasyon dalgalanmasına ilçeler bazında bakıldığında, 2014 yılında Bismil (Kazancı)'de (28 birey/tuzak) ve Çınar (Karalar)'da (23 birey/tuzak) Mayıs ayı sonunda en yüksek popülasyon yoğunluğuna ulaştığı görülürken aynı yıl Sur (Tanoğlu)'da (13 birey/tuzak) Haziran ayı başında en yüksek popülasyon yoğunluğu görülmüştür. 2015 yılında ise eşeysel çekici feromon tuzaklarda Sur (Tanoğlu)'da (6 birey/tuzak) Temmuz ayı başında, Bismil (Kazancı)'de (19 birey/tuzak) ve Çınar (Karalar)'da (15 birey/tuzak) Temmuz ayı ortalarında en yüksek popülasyon yoğunluğuna ulaştığı görülmüştür.

Anahtar Kelimeler: Helicoverpa armigera, Popülasyon Dalgalanması, Pamuk, Diyarbakır, Türkiye

\section{ABSTRACT}

Helicoverpa armigera Hübner (Lepidoptera: Noctuidae) is one of the most significant pests in cotton. $H$. armigera adult causes crop losses in cotton especially generative organs by doing damage and its damage varies according to months and years. This study was realized on in the years of 2014 and 2015 in Diyarbakır province in order to catch of pheromone traps in observing the population fluctuation of $\mathrm{H}$. armigera in the cotton fields. Experiments were conducted in three locations (Bismil, Çınar and Sur) with nine cotton fields. Delta type pheromone traps were used in this experiments. Three of each pheromone traps were put in the cotton fields. Trapped adults were counted at weekly intervals. In this study was found to have caught more adult in the traps during the in 2014, but it was found that there were fewer catches in the traps in 2015 than in the previous year. The adult of the $H$. armigera was determined in May and reached to maximum level in end of May pheromone traps in Bismil (Kazancı) (28 moths/trap) and Çınar (Karalar) (23 moths/trap) in 2014 and at the same year reached to maximum level 
in June pheromone traps in Sur (Tanoğlu) (13 moths/trap). Contrary, the adult population was reached to maximum level at the beginning of July pheromone traps in Sur (Tanoğlu) (6 moths/trap) in 2015 and at the same year reached to maximum level in Bismil (Kazancı) (19 moths/trap) and Çınar (Karalar) (15 moths/trap) in mid-July.

Key Words: Helicoverpa armigera, Population Fluctuation, Cotton, Diyarbakır, Turkey

\section{Giriş}

Pamuk (Gossypium hirsitum) ikiçenekliler (Dicotyledoneae) sınıfının ebegümecigiller (Malvaceae) familyasından olup lif ve yağ elde etmek amacıyla tropik ve subtropik alanlarda tarımı yapılan bir bitkidir (Anonim 1996). Tarımsal faaliyetlerde önemli bir bölüm geçimini pamuktan sağlarken pamuğa dayalı olan dokuma, iplik ve yağ sektörü sanayisinde ise hammadde kaynağı konumundadır. Pamuk; tarımı ve sanayisi ile geniş bir iş alanı sağlarken lifi ile tekstil sanayisine, çiğidi ile yağ sanayisine, küspesi ile hayvancılık sektörüne, ihracatı ile dış ticarete çok önemli katkıları olan endüstriyel bir tarım ürünüdür. Verim ve lif kalitesi özelliklerinin iyileştirilmesi için erken jenerasyon seçimlerinin yapılması uygundur (Temiz ve ark., 2016). Artan dünya nüfusuna paralel olarak sanayileşen ve refah düzeyi yükselen ülkelerde pamuk tarımında üretim ve tüketim miktarı artmaktadır. Uluslararası Pamuk İstişare Kurulunun (ICAC) 2012-2016 arası 5 yıllık döneme ait verileri incelendiğinde; dünyada ortalama 32.7 milyon hektar alanda pamuk ekimi yapıldığı görülmektedir. 2015/2016 sezonu tahminlerine göre dünyada pamuk üretim alanı en geniş olan ülke Hindistan ardından Çin, $A B D$, Pakistan, Özbekistan ve Brezilya gelmektedir (Anonim 2015).

Türkiye başta ihracat ürünlerinden biri olması ve ayrıca ülkemizin en gelişmiş sanayi dallarından biri olan dokumacılık kesimine hammadde oluşturması sebebiyle Uluslararası Pamuk İstişare Kurulunun (ICAC) verilerine göre 475 bin hektar pamuk ekim alanı ile 9. sırada, 1.5 milyon ton pamuk tüketimi ile 4. sırada bulunmaktadır (Anonim 2015). Son yıllarda pamuk üretimine uygun tarım ve iklim koşullarına sahip olması ve sulamaya açık alanların artmasıyla beraber Güneydoğu Anadolu Bölgesi'nde pamuk ekim alanlarının artacağı tahmin edilmektedir (Bayhan ve ark. 2015). Ekim alanlarının genişliği bakımından ilk sırayı Güneydoğu Anadolu Bölgesi almaktadır. Güneydoğu Anadolu Bölgesi 2015 yılı verilerine göre, 264.5 bin ha ekiliş alanı ve 427.4 bin ton pamuk üretimi ile ülke üretiminin \% 57.9'unu oluşturmuştur. Güneydoğu Anadolu Bölgesinde pamuk üretimi en fazla yapılan illerin başında Diyarbakır ili gelmektedir. Türkiye önemli pamuk üretim alanının \% 11.83’ ünü 43017 bin ha ile Diyarbakır ili oluşturmaktadır. Diyarbakır ilinde Bismil, Merkez (Kayapınar, Yenişehir, Sur, Bağlar), Çınar ve Silvan ilçelerinin diğer ilçelere oranla daha fazla üretim potansiyeline sahip olduğu ve toplam ekim alanının \% 96.73' ünü bu ilçelerin oluşturduğu belirtilmektedir (TÜiK 2015).

Çizelge 2. Türkiye pamuk ekim alanlari (Bin ha)

Table 2. Turkey cotton cultivation areas (Thousand ha)

\begin{tabular}{|l|l|l|l|l|l|}
\hline YIl & Ege & $\begin{array}{l}\text { Güneydoğu } \\
\text { Anadolu }\end{array}$ & Antalya & Çukurova & Toplam \\
\hline 2010 & 82.6 & 287.8 & 4.1 & 97.7 & 472.2 \\
\hline 2011 & 96.7 & 313.9 & 5.8 & 114 & 530.4 \\
\hline 2012 & 82.7 & 302.2 & 5.7 & 91.4 & 482.0 \\
\hline 2013 & 82.6 & 278.9 & 5.9 & 78.7 & 446.1 \\
\hline 2014 & 93.4 & 289.4 & 5.6 & 75.2 & 463.6 \\
\hline 2015 & 91.7 & 264.5 & 6.2 & 71.6 & 434.0 \\
\hline
\end{tabular}

Kaynak: TUiK, 2015 (http://www.tuik.gov.tr)

Sulamaya açılan alanlarla ekim alanlarının artması beraberinde pamukta zararlı, hastalık ve yabancı ot gibi bitki koruma sorunlarını da artıracağı ifade edilmiştir (Bayhan ve ark., 2015). Bu nedenle pamuk tarımında bitkinin ekiminden hasadına kadar çeşitli dönemlerde bazı hastalık zararlı ve yabancı otlar önemli ürün kayıplarına sebep olmak ile beraber aynı zamanda ürün maliyetinin artmasına da neden olmaktadır. Bölgemizde bugüne kadar yürütülen araştırmalarda ise önemli zararlılardan birisinin Yeşilkurt olduğu araştırıcılar tarafından belirtilmiştir (Karaat ve ark., 1986; Göven ve Efil, 1994).

Bölgemiz Diyarbakır ilinde GAP projesiyle sulama alanlarının artması ile pamuk ekim alanlarında artış meydana gelmesinden dolayı bu 
araştırma ile amaçlanan bölgemiz pamuk ekim alanlarında ekonomik açıdan zarara neden olan Yeşilkurt 'un popülasyon dalgalanmasını belirlemektir. Eşeysel çekici feromon tuzaklarla gerçekleştirilen popülasyon takibi sonucu elde edilen verilerin zararlının kimyasal mücadelesine yönelik önemli katkılarda bulunacağı ve ileride mücadelesine yönelik konularda yapılacak çalışmalara bilimsel veriler oluşturacağı düşünülmektedir.

\section{Materyal ve Metot}

Çalışmada Delta tipi eşeysel çekici feromon tuzaklar kullanılmıştır. Helicoverpa armigera'nın ergin popülasyon dalgalanmasını belirlemek amacıyla 2014-2015 yıllarında Diyarbakır ili Bismil (Kazancı köyü), Çınar (Karalar köyü) ve Sur (Tanoğlu köyü) ilçelerinde her biri en az 30 dekar olan ve yaklaşık üç bölüme ayrılmış 3 adet pamuk tarlasında yürütülmüştür. Eşeysel çekici feromon tuzaklar pamuğun çıkış zamanından itibaren 30 dekara üç adet olacak şekilde ve yaklaşık $1.5 \mathrm{~m}$ uzunluğunda askı biçiminde yaptırılmış demir çubuklara asılarak tarlalara yerleştirilmiştir (Şekil 1).

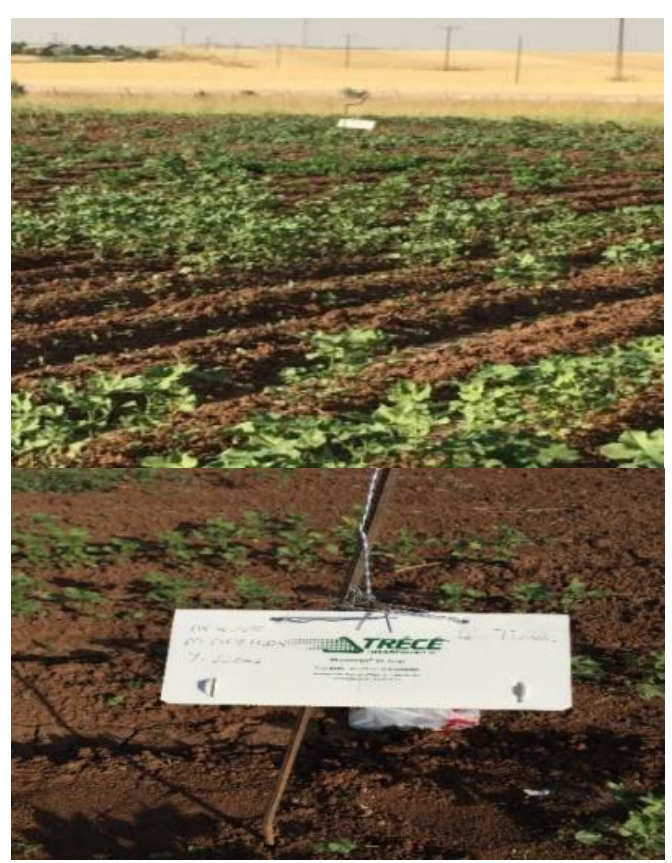

Şekil 1. Helicoverpa armigera'nın ergin çıkışlarını takip etmek için tarlalara yerleştirilen feromon tuzaklar (Tanoğlu Köyü)

Figure 1. Pheromone traps placed in the fields to follow the mature outbreaks of Helicoverpa armigera (Tanoğlu village)

Eşeysel çekici feromon tuzakların kapsülleri bütün tuzaklarda aynı tarihe denk gelecek şekilde 4 haftada bir, yapışkan tablalar ise gerekli görüldükçe değiştirilmiştir. Değiştirilen yapışkan tabla ve feromon kapsüller tarladan uzaklaştırılmış ve yerlerine yenileri konulmuştur.

Popülasyon takibinde haftalık olarak yapılan sayımlarda tuzaklarda yakalanan zararlı erginleri tuzaklardan temizlenmiştir. Sayımlar yaklaşık hasat dönemi başlayana kadar devam etmiştir. Çalışmanın değerlendirilmesinde tuzaklarda yakalanan erginler esas alınmıştır.

\section{Bulgular ve Tartışma}

Popülasyon değişiminin takibi için pamuk ekimi yapılan tarlalarda feromon tuzaklar 2014 yılında Sur (Tanoğlu) ilçesine ilk olarak 25.04.2014 tarihinde, 2015 yılında ise 08.05.2015 yılında tarlalara yerleştirilmiş ancak bu yıla ait olumsuz hava koşullarından tuzakların ve pamuk tohumlarının yoğun yağış sebebiyle zarar görmeleri sebebiyle üreticilerin çalışmanın yürütülmesi için belirlenen arazilerde yeniden ekim yapmalarından dolayı 18.05.2015 tarihinde tekrar yerleştirilmiştir. Garcia ve Garcia (1990) İspanya'da yürüttükleri araştırmada yağışların tuzaklarda yakalanma etkinliğini olumsuz etkilediği ve azalttığını belirtmişlerdir.

Pamuk tarlalarına 2014 yılında asılan Delta tipi eşeysel çekici feromon tuzaklarında, Tanoğlu köyünde sıcaklığın $20{ }^{\circ} \mathrm{C}$ ve orantılı nemin $\% 52$ olduğu 5 Mayıs tarihinde ilk erginler (5 birey/tuzak) saptanmıştır. Sıcaklığın $23{ }^{\circ} \mathrm{C}$ ve orantılı nemin \% 22 olduğu 9 Haziran 'da (13 birey/tuzak), sıcaklığın $27{ }^{\circ} \mathrm{C}$ ve orantılı nemin \% 47 olduğu 21 Temmuz 'da (8 birey/tuzak) iki tepe noktası oluşturmuştur. Bu tarihlerden sonra ergin popülasyonunda önemli artışlar olmamasına rağmen 11 Ağustos ve 25 Ağustos tarihlerinde tuzaklarda az da olsa ergin yakalanmış ve en son 8 Eylül tarihinde tuzaklarda son erginlerin yakalandığı gözlenmiştir. Tanoğlu köyünde pamuk tarlalarına 2015 yılında 17.05.2015 tarihinde asılan eşeysel çekici feromon tuzaklarında ise, ilk erginler sıcaklığın $24{ }^{\circ} \mathrm{C}$ ve orantılı nemin \% 42 olduğu 8 Haziran tarihinde görülmüş (4 
birey/tuzak), sıcaklığın $29{ }^{\circ} \mathrm{C}$ ve orantılı nemin \% 24 olduğu 6 Temmuz'da (6 birey/tuzak) tepe noktası yaptığı bu tarihten itibaren Yeşilkurt ergin popülasyonunda giderek azalma olduğu görülmüştür. Bu tarihten itibaren Yeşilkurt popülasyonunda düşüş olmasına rağmen Yeşilkurt erginleri eşeysel çekici feromon tuzaklarda 24 Ağustos tarihinde tekrar görülmüş ve düzenli olmayan bu popülasyon dalgalanması eylül ayı ilk haftasından itibaren sıfır seviyesine inmiştir (Şekil 2. ve 3.).

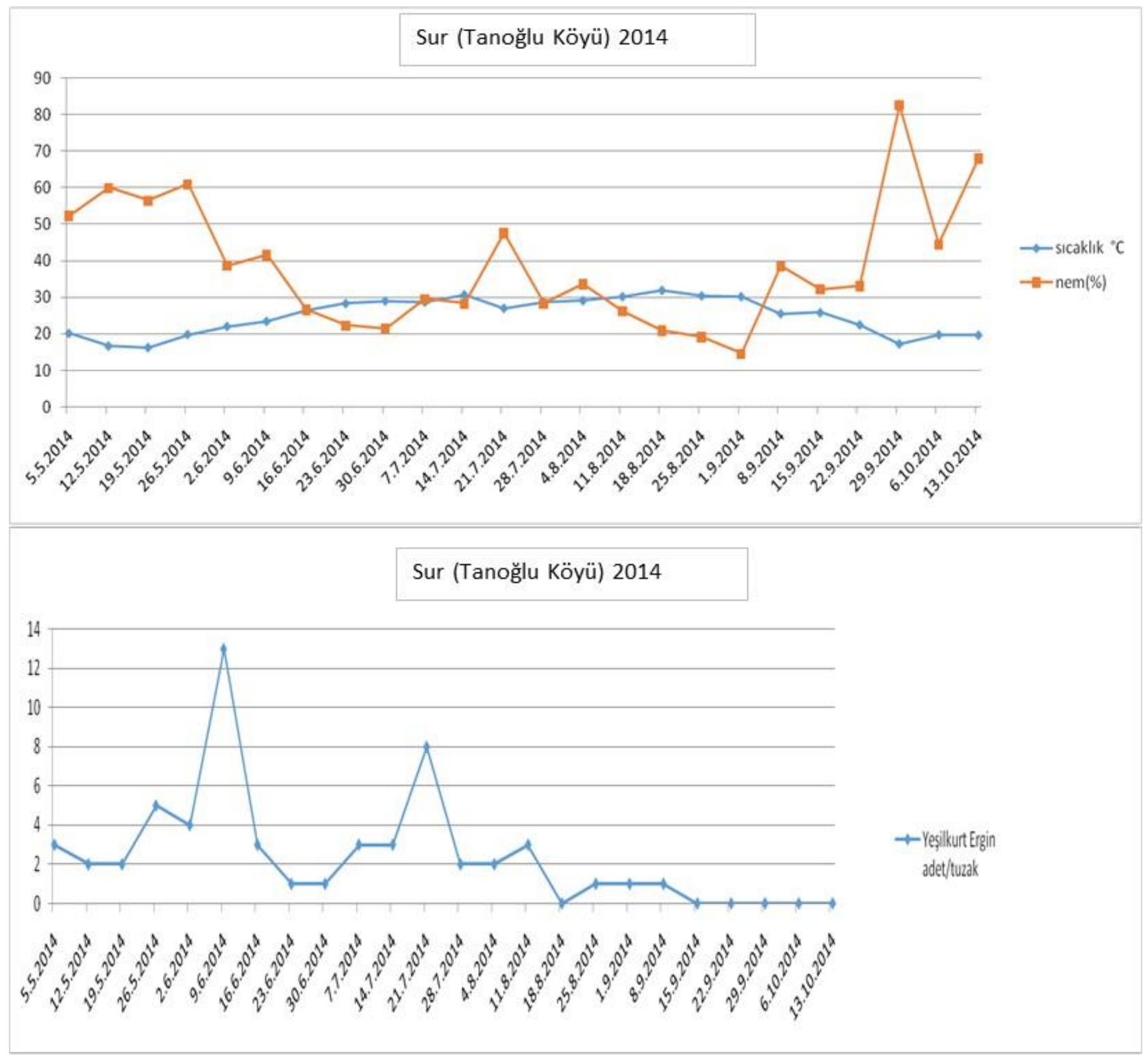

Şekil 2. Sur (Tanoğlu) ilçesindeki 2014 yılı haftalık sıcaklık-nem değeri ve Helicoverpa armigera'nın eşeysel çekici feromon tuzaklarındaki popülasyon gelişimi

Figure 2. Population development in Helicoverpa armigera in the province of Sur (Tanoğlu) in 2014 weekly temperaturehumidity value and sexual attractiveness pheromone traps 


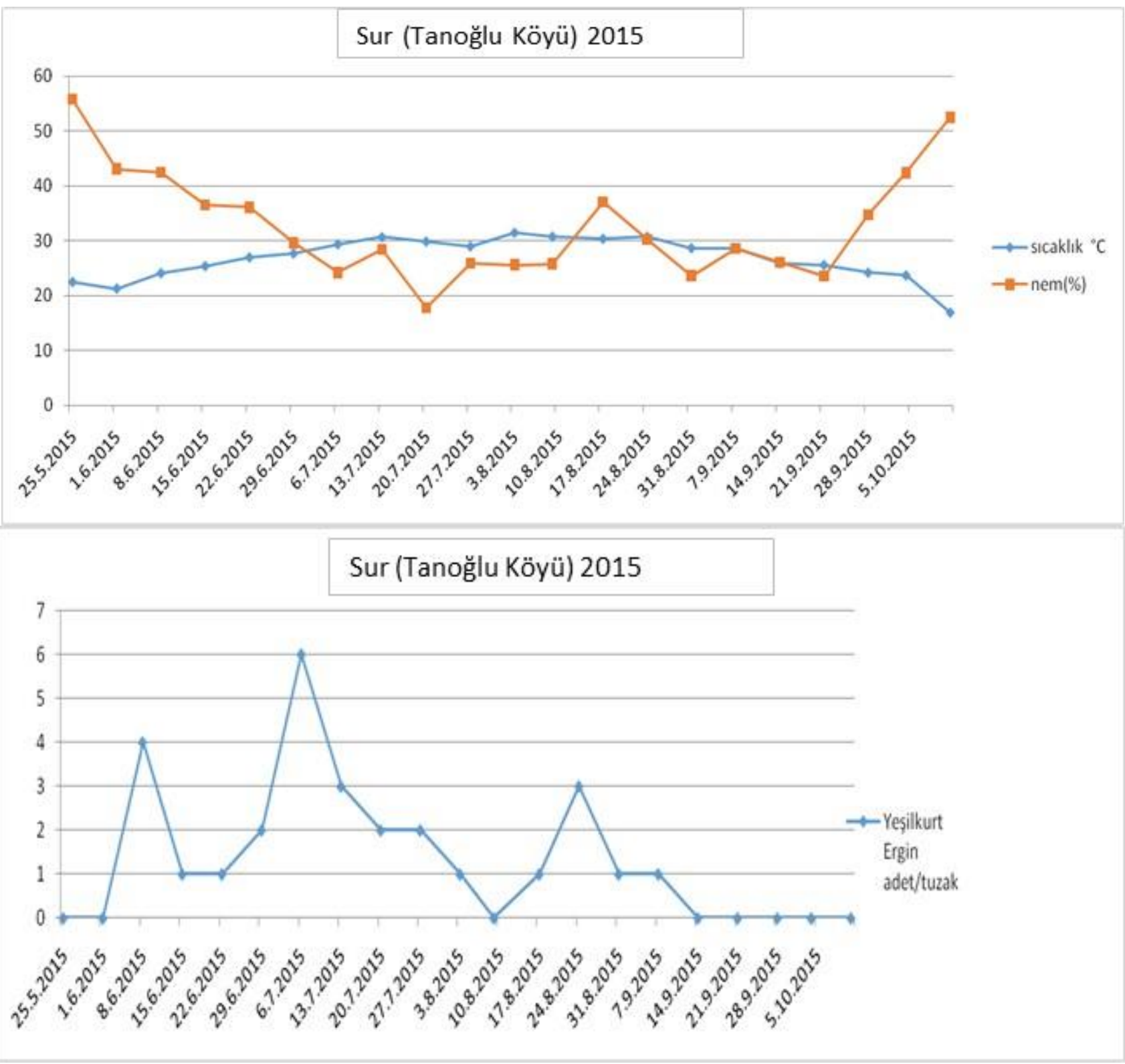

Şekil 3. Sur (Tanoğlu) ilçesindeki 2015 yılı haftalık sıcaklık-nem değeri ve Helicoverpa armigera'nın eşeysel çekici feromon tuzaklarındaki popülasyon gelişimi

Figure 3. Population development of Helicoverpa armigera in the province of Sur (Tanoğlu) in 2015 weekly temperaturehumidity value and sexual attractiveness pheromone traps

Pamuk tarlalarına 22.04.2014 tarihinde asılan Delta tipi eşeysel çekici feromon tuzaklarda Çınar ilçesi Karalar köyünde sıcaklığın $16{ }^{\circ} \mathrm{C}$ ve orantılı nemin \% 54 olduğu 3 Mayıs tarihinde tuzaklarda ilk erginler (4 birey/tuzak) saptanmıştır. Sıcaklığın $19{ }^{\circ} \mathrm{C}$ ve orantılı nemin \% 63 olduğu 24 Mayıs 'ta (23 birey/tuzak) ilk tepe noktası olmasına rağmen bu tarihten sonra ergin popülasyonunda hızlı bir düşüş meydana gelmiş ve sıcaklığın $30{ }^{\circ} \mathrm{C}$ ve orantılı nemin \% 33 olduğu 27 Temmuz 'da (17 birey/tuzak) ikinci tepe noktası oluşmuştur. Tuzaklarda yakalanan ergin popülasyonunda tekrar düşüş yaşanmış ve sıcaklığın $31{ }^{\circ} \mathrm{C}$ ve orantılı nemin \% 21 olduğu 17 ağustos tarihinde (13 tuzak/birey) tekrar bir tepe noktası meydana gelmiştir. Eylül ayı ilk haftasından itibaren yakalanmalar azalmasına rağmen en son erginler 8 Ekim tarihinde görülmüştür. Karalar köyünde pamuk tarlalarına 2015 yılında 16.05.2015 tarihinde asılan eşeysel çekici feromon tuzaklarda ise ilk erginler sıcaklığın $20^{\circ} \mathrm{C}$ ve orantılı nemin \% 64 olduğu 23 Mayıs tarihinde (1 birey/tuzak) görülmüş, sıcaklığın $29{ }^{\circ} \mathrm{C}$ ve orantılı nemin \% 35 olduğu 10 Temmuz'da (15 birey/tuzak) tepe noktası yaptığı bu tarihten itibaren tuzaklarda yakalanan Yeşilkurt ergin popülasyonunda giderek azalma olduğu ve sıcaklığın $30^{\circ} \mathrm{C}$ ve orantılı nemin \% 33 olduğu 15 Ağustos tarihinde (9 birey/tuzak) tekrar tepe noktası oluşturduğu görülmüştür. Eylül ayı son haftasından itibaren eşeysel çekici feromon tuzaklarda yakalanan ergin birey sayısı oldukça azalmıştır (Şekil 4. ve 5.). 


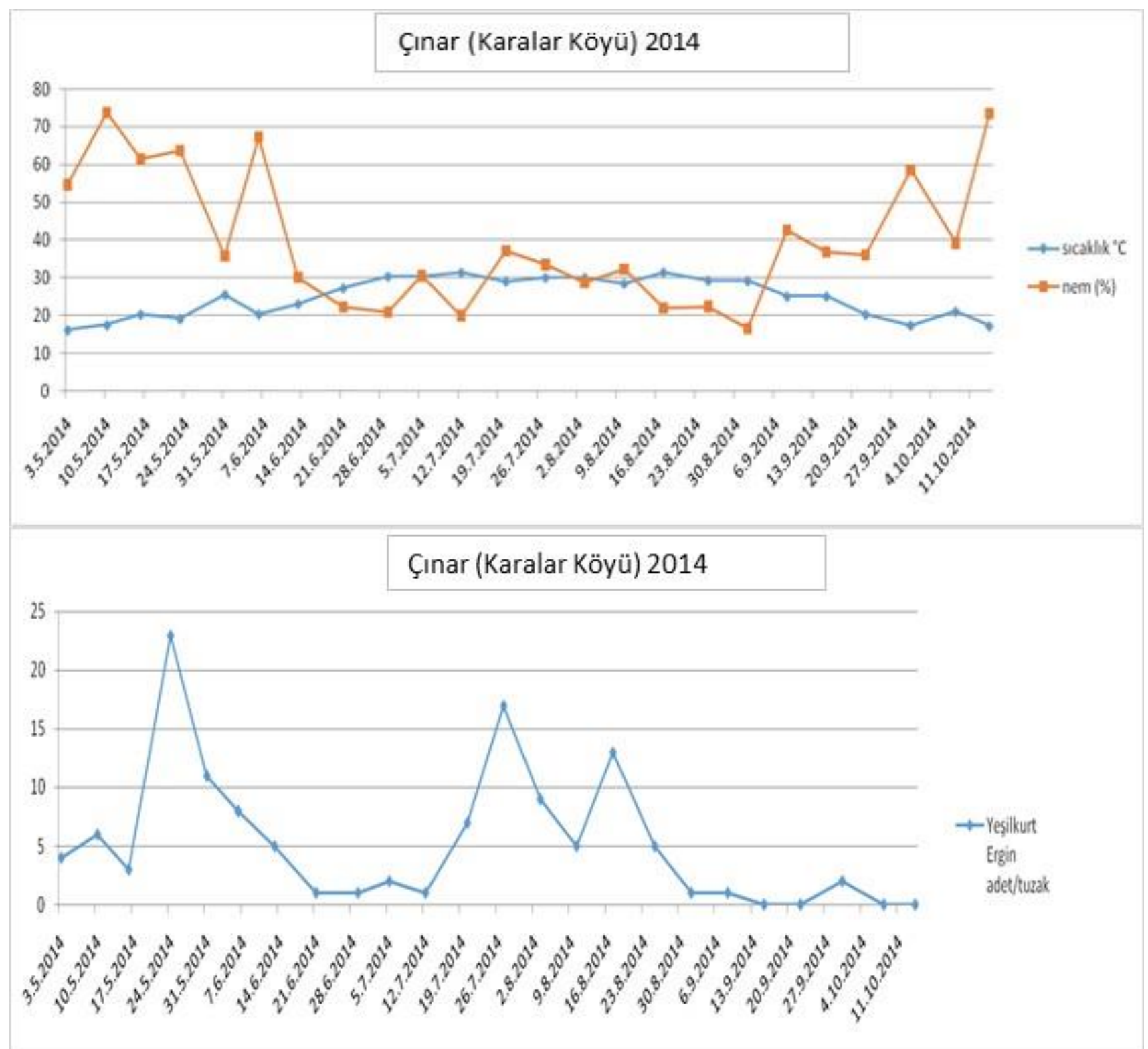

Şekil 4. Çınar (Karalar) 2014 yılı haftalık sıcaklık-nem değerleri ve Helicoverpa armigera'nın eşeysel çekici feromon tuzaklarındaki popülasyon gelişimi

Figure 4. Population development of Helicoverpa armigera in the province of Çınar (Karalar) in 2014 weekly temperaturehumidity value and sexual attractiveness pheromone traps

Pamuk tarlalarına 22.04.2014 tarihinde asılan Delta tipi eşeysel çekici feromon tuzaklarda Bismil ilçesi Kazancı köyünde sıcaklığın $19{ }^{\circ} \mathrm{C}$ ve orantılı nemin \% 53 olduğu 5 Mayıs tarihinde (2 birey/tuzak) tuzaklarda ilk erginler saptanmıştır. Sıcaklığın $20^{\circ} \mathrm{C}$ ve orantılı nemin \% 56 olduğu 26 Mayıs 'ta (28 birey/tuzak) ilk tepe noktası olmasına rağmen bu tarihten sonra ergin popülasyonunda hızlı bir düşüş meydana gelmiş ve sıcaklığın $26{ }^{\circ} \mathrm{C}$ ve orantılı nemin \% 51 olduğu 21 Temmuz'da (20 birey/tuzak) ikinci tepe noktası oluşmuştur. Eşeysel çekici Feromon tuzaklarda yakalanan ergin popülasyonunda düşüş yaşanmış ve sıcaklığın $25^{\circ} \mathrm{C}$ ve orantılı nemin $\% 42$ olduğu 8 Eylül tarihinde (8 birey/tuzak) tekrar bir tepe noktası meydana gelmiştir. En son erginler 6 Ekim tarihinde görülmüştür. Kazancı köyünde pamuk tarlalarına 2015 yılında 18.05.2015 tarihinde asılan eşeysel çekici feromon tuzaklarda ise ilk erginler sıcaklığın $20{ }^{\circ} \mathrm{C}$ ve orantılı nemin \% 64 olduğu 25 Mayıs tarihinde (3 birey/tuzak) görülmüş, sıcaklığın $29{ }^{\circ} \mathrm{C}$ ve orantılı nemin \% 34 olduğu 13 Temmuz 'da (19 birey/tuzak) tepe noktası yaptığı bu tarihten itibaren eşeysel çekici feromon tuzaklarda yakalanan Yeşilkurt ergin popülasyonunda giderek azalma olduğu ve sıcaklığın $30{ }^{\circ} \mathrm{C}$ ve orantılı nemin \% 36 olduğu 9 Ağustos tarihinde (8 birey/tuzak) tekrar tepe noktası oluşturduğu görülmüştür. Eylül ayı son haftasından itibaren tuzaklarda yakalanan ergin birey sayısı oldukça azalmıştır (Şekil 6. ve 7.). 


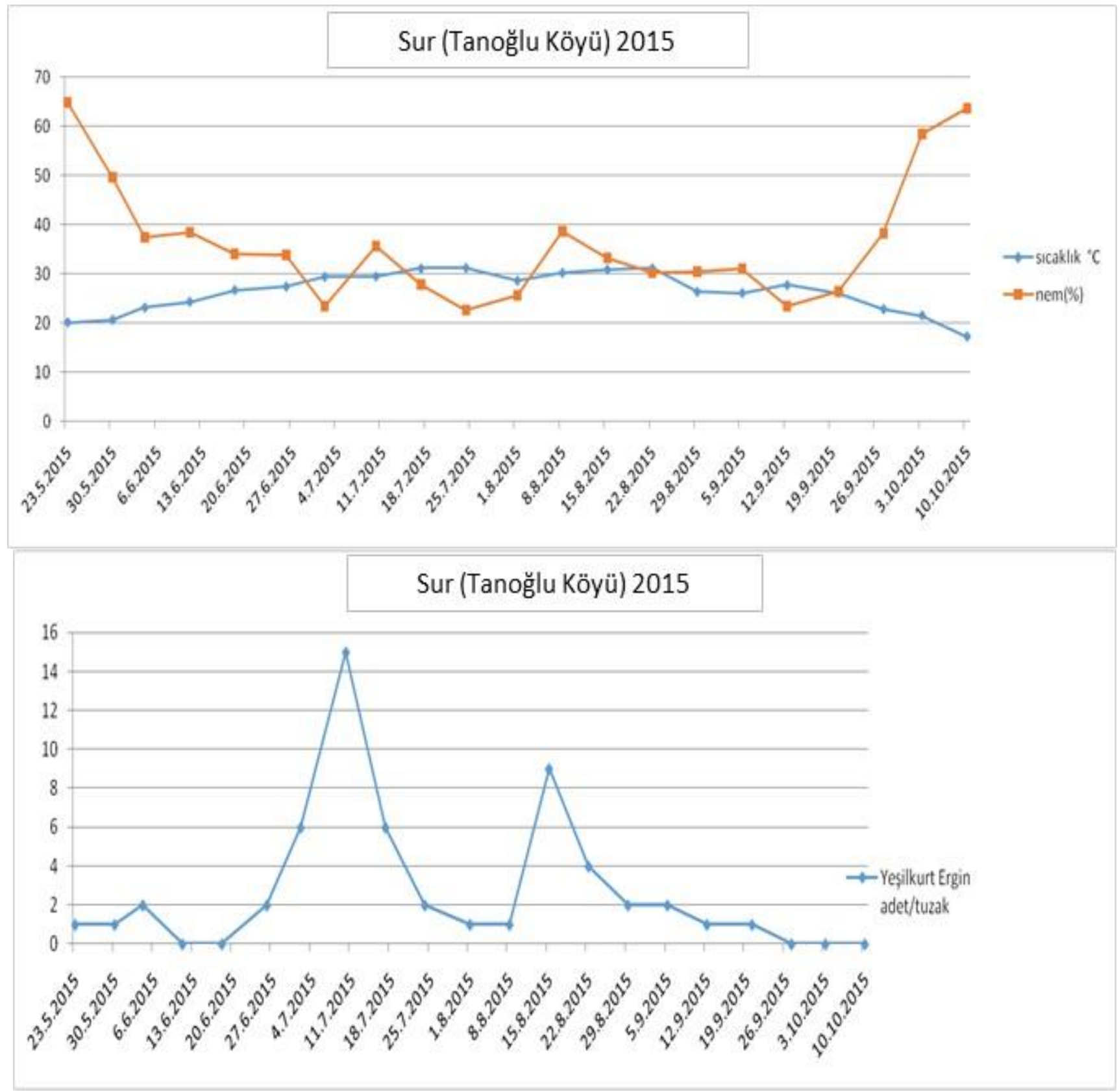

Şekil 5. Çınar (Karalar) 2015 yılı haftalık sıcaklık-nem değerleri ve Helicoverpa armigera'nın eşeysel çekici feromon tuzaklarındaki popülasyon gelişimi

Figure 5. Population development of Helicoverpa armigera in the province of Çınar (Karalar) in 2015 weekly temperaturehumidity value and sexual attractiveness pheromone traps

İlk ergin kelebeklerin ortaya çıkış tarihleri bakımından aynı bölgede yıllar arasında farklılık meydana geldiği görülmüştür. 2014 yılında Kazancı (Bismil) ve Karalar (Çınar) köyünde bulunan pamuk tarlalarında yapılan sayımlarda ilk erginlerin mayıs ayı başından itibaren görüldüğü, popülasyon artışının mayıs ayının son haftasına kadar sürdüğü ve ilk tepe noktasına mayıs ayı sonunda ulaşıldığı, Tanoğlu (Sur) köyünde ise ilk tepe noktasının haziran ayında meydana geldiği görülmüştür. Bu tarihten itibaren popülasyon dalgalanmasında azalmalar görülmüş ancak temmuz ayı ortasından itibaren tekrar artarak her üç köyde de ikinci tepe noktası meydana gelmiştir. Ağustos ayı boyunca küçük dalgalanmalar şeklinde devam eden popülasyonda Karalar köyünde üçüncü kez tepe noktası meydana gelmiştir ve en son erginlere tuzaklarda ekim ayında rastlanırken Kazancı ve Tanoğlu köyünde son erginlere eylül ayında rastlanmış ve bu aydan itibaren ergin uçuşu sona ermiştir. Öngören ve ark. (1977), İzmir (Menemen ile Narlıdere)' e yerleştirilen ışık tuzaklarında ilk ergin bireylerin 15 ile 28 Mayıs'ta yakalandığını belirtmişlerdir. Yabaş ve Özer (1983) yürüttükleri bir çalışmada, Çukurova Bölgesi'ne yerleştirilen ışık tuzaklarında $H$. armigera'ya ait ilk ergin bireylerin 1978 yılının mayıs ayı son haftasında, 
1979 yılında ise nisan ayı son haftasında, son Yunanistan'da yürüttükleri çalışmalarında ise $H$. erginlerinin ise ekim ayında yakalandığını armigera erginlerinin mayıs ayından ekim ayına belirtmişlerdir. Tsisitpis ve Alexandri (1990) ise, kadar yakalandığını belirtmişlerdir.

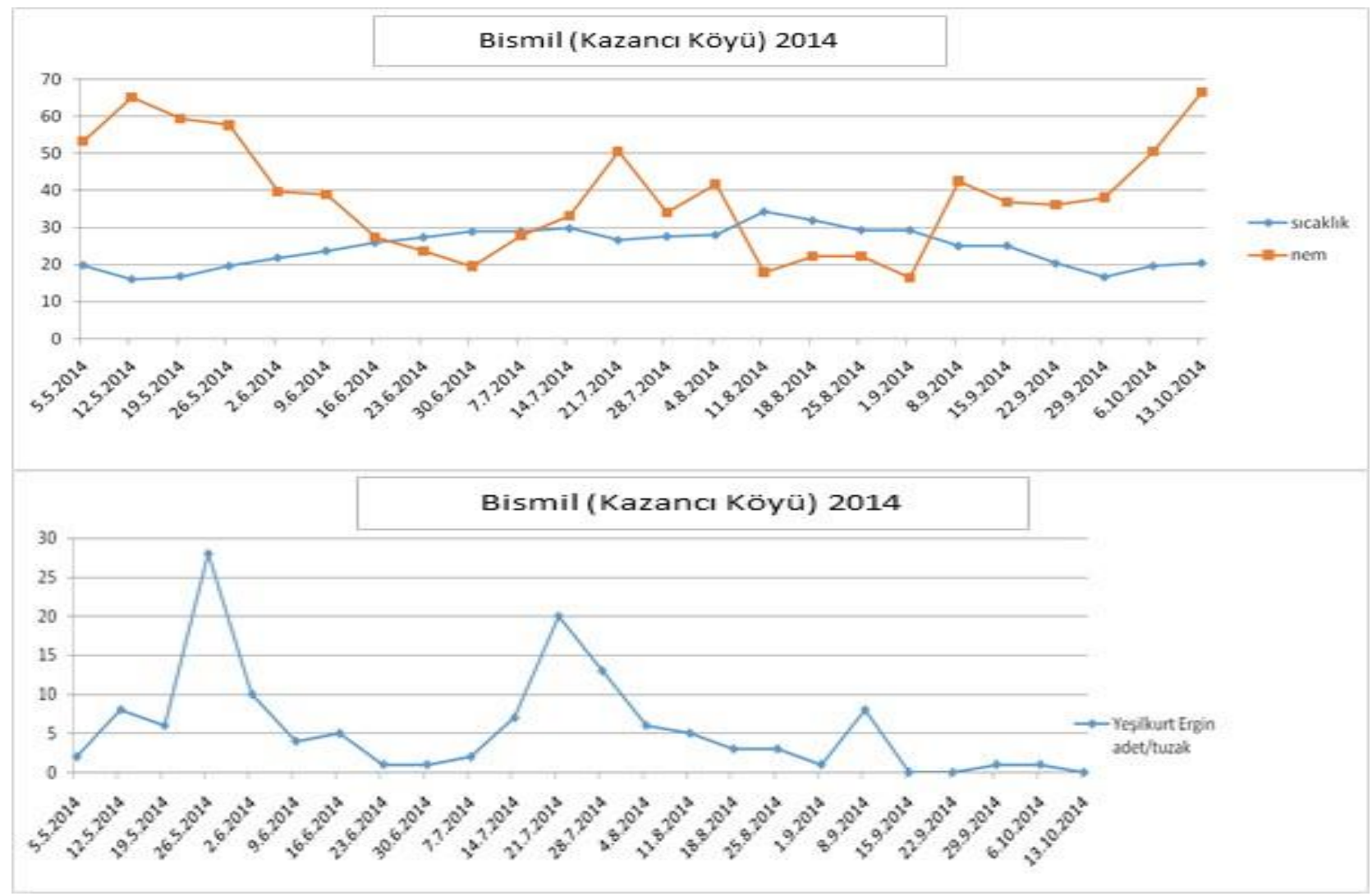

Şekil 6. Bismil (Kazancı) 2014 yılı haftalık sıcaklık-nem değerleri ve Helicoverpa armigera'nın eşeysel çekici feromon tuzaklarındaki popülasyon gelişimi

Figure 6. Population development of Helicoverpa armigera in the province of Bismil (Kazancl) in 2014 weekly temperaturehumidity value and sexual attractiveness pheromone traps

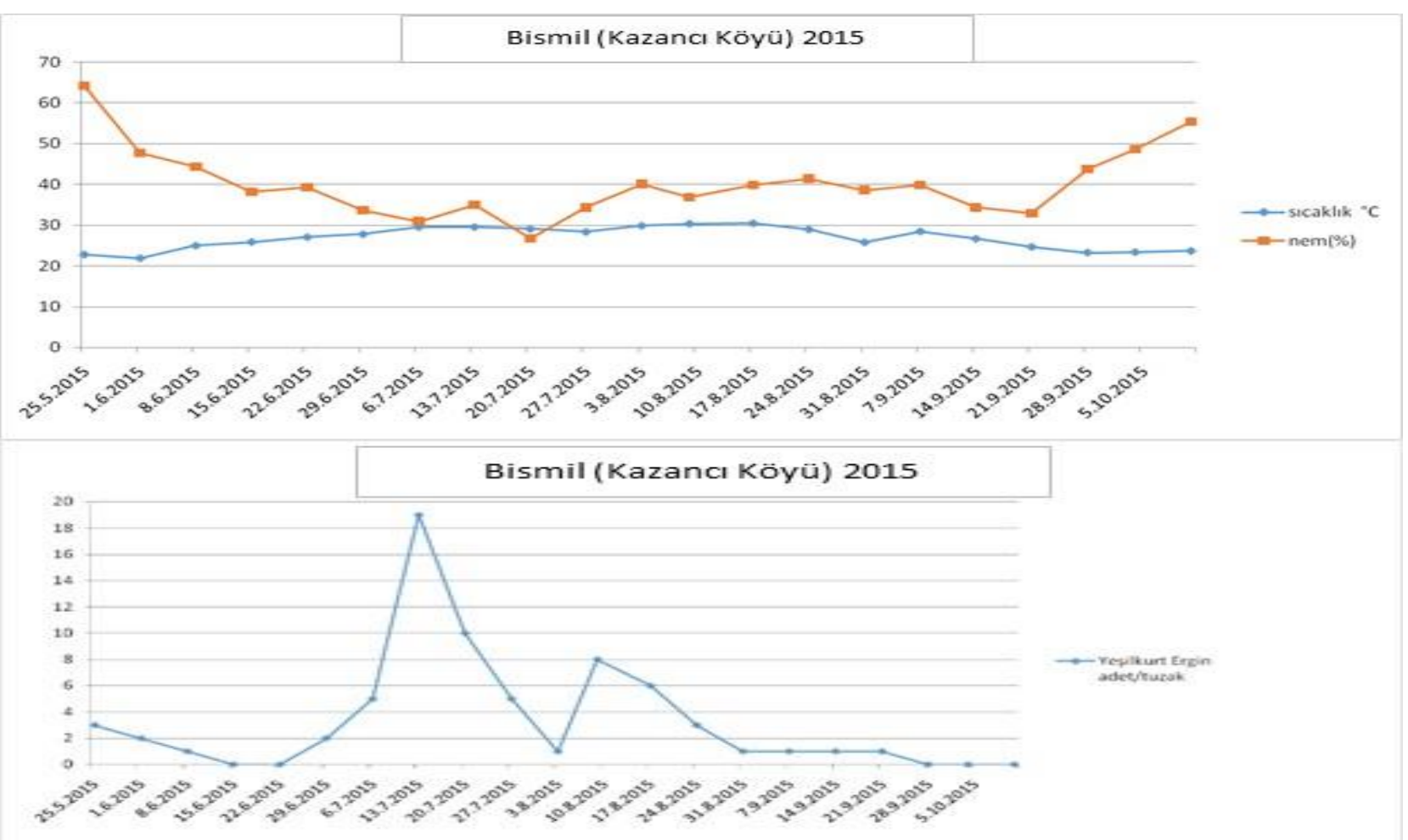

Şekil 7. Bismil (Kazancı) 2015 yılı haftalık sıcaklık-nem değerleri ve Helicoverpa armigera'nın eşeysel çekici feromon tuzaklarındaki popülasyon gelişimi

Figure 7. Population development of Helicoverpa armigera in the province of Bismil (Kazancl) in 2015 weekly temperaturehumidity value and sexual attractiveness pheromone traps 
2015 yılında tuzakların olumsuz hava koşulları sebebiyle tekrardan tarlalara yerleştirildiği tarih olan haziran ayı başında Tanoğlu köyünde ilk tepe noktası oluşmuş, Kazancı köyü ve Karalar köyünde ise ilk tepe noktası Temmuz ayında meydana gelmiştir. Tanoğlu köyünde ikinci tepe noktası temmuz ayı ortasında, üçüncü tepe noktası ise ağustos ayında görülürken Kazancı ve Karalar köyünde ki tarlalarda yapılan sayımlarda ise ikinci tepe noktasına ağustos ayı ortasında rastlanmıştır. $\mathrm{Bu}$ tarihlerden itibaren her üç köyde yürütülen çalışmalarda eylül ayı başından itibaren popülasyon yoğunluğu oldukça azalmış ve tamamen bitmiştir. Kaya (2008) Hatay'da, yazlık ve kışlık ekimi yapılan sebze alanlarında ışık tuzaklarıyla yürüttüğü çalışmasında Yeşilkurt'a ait ilk ergin bireylerin 11 Haziran tarihinde görüldüğünü bildirmiştir. Elde edilen bu bilgiler ile yapılan bu çalışma arasında az da olsa benzerlik olduğu görülmektedir. Delta tipi eşeysel çekici feromon tuzaklarla yürütülen bu çalışmada değerlendirme aşamasında tuzaklardaki yakalanmalar esas alınmış, Yeşilkurt ergin bireylerin yapışkan tablaya yapışması ile sayım yapılarak popülasyon yoğunluğu takibi yapılmıştır. Ancak ergin bireylerin yapı gereği iri olmalarından dolayı yapışkan tabladan kendisini kurtarabildiği veya tuzakların yere düşüp yapışkan tablada oluşan toz sebebiyle ve aşırı sıcaklarda ya da rüzgârlı havalarda meydana gelen olumsuzluklardan dolayı yapışkan tabla etkinliğinde azalmalar meydana geldiğinden ve bu durumların ortaya çıkmasından dolayı bazen sayım etkinliği olumsuz etkilenmiştir. Eşeysel çekici feromon tuzaklarla gerçekleştirilen bu çalışmada, $H$. armigera'nın popülasyon takibi ile elde edilen verilerin zararlının ilaçlı mücadelesine yönelik önemli faktör olan mücadele zamanının belirlenmesinde başarıyı etkileyeceği ve önemli bir unsur olacağı düşünülmektedir.

\section{Sonuç ve Öneriler}

Güneydoğu Anadolu Bölgesi Diyarbakır ili pamuk ekim alanlarındaki en önemli zararlılardan birisi olan Yeşilkurt (Helicoverpa armigera)'un ergin popülasyon takibi üzerine bu çalışma yürütülmüştür.

Helicoverpa armigera 'nın popülasyon dalgalanması 2014 ve 2015 yıllarında genel olarak aylara ve yıllara göre farklılık göstermiştir. Deneme kurulan tarlalarda 2014 yılında yapılan sayımlarda tuzaklarda daha fazla kelebek yakalanmasının olduğu görülürken 2015 yılında geçen yıla oranla tuzaklarda daha az yakalanma olduğu tespit edilmiştir. Yeşilkurt ergin popülasyon dalgalanmasına bakıldığı zaman 2014 yılında Bismil (Kazancı) ve Çınar (Karalar)'da mayıs ayı sonunda en yüksek popülasyon yoğunluğuna ulaştığı görülürken aynı yıl Sur (Tanoğlu)'da haziran ayı başında en yüksek popülasyon yoğunluğu görülmüştür. 2015 yılında ise tuzakların yağış sebebi ile tekrardan yerleştirilmesi neticesinde Sur (Tanoğlu)'da temmuz ayı başında, Bismil (Kazancı) ve Çınar (Karalar)'da temmuz ayı ortalarında en yüksek popülasyon yoğunluğuna ulaştığı görülmüştür.

Popülasyon dalgalanmasını belirlemek amacıyla yürütülen bu çalışmada ergin bireylerin eşeysel çekici feromon tuzaklarla izlenmesiyle mücadele zamanını belirleme ve mücadeleye karar verme açısından önemli olduğu sonucuna varılmıştır. Eşeysel çekici feromon tuzakların ergin birey popülasyon yoğunluğu değişiminin izlenmesinde kullanılması, zararlıya yönelik mücadeleye karar vermede ise tarlada yapılacak larva yoğunluğu sayımlarının esas alınması gerekmektedir. Yeşilkurt' un ilaçlı mücadelesinde başarıyı etkileyen önemli faktör durumundaki ilaçlama zamanını belirlenmesinde ise ergin birey popülasyonunun izlenmesinin önemi dikkate alındığında, eşeysel çekici feromon tuzaklar mücadele zamanının belirlenmesinde önemli bir faktör olacaktır.

\section{Ekler}

Bu Çalışma, "Diyarbakır ili Pamuk Ekim Alanlarında Bulunan Yeşilkurt, Helicoverpa armigera (Hübner) (Lepidoptera: Noctuidae)'un Popülasyon Dalgalanmasının Belirlenmesi" adlı yüksek lisans çalışmasının bir bölümüdür. Bu 
çalışma Dicle Üniversitesi Bilimsel Araştırma Projeleri Koordinatörlüğü (DÜBAP) tarafından 14ZF-99 nolu proje ile desteklenmiştir.

\section{Kaynaklar}

Anonim, 1996. Türk Tarımında Pamuğun Yeri ve Önemi. Erişim: (http://www.ito.org.tr/itoyayin/0012665.pdf) Erişim Tarihi: 22.05.2016

Anonim, 2015. T.C. Gümrük ve Ticaret Bakanlı̆̆ı Kooperatifçilik Genel Müdürlüğü Erişim:(http://koop.gtb.gov.tr) Erişim Tarihi: 27.05.2016

Bayhan, E., Sağır, A., Uygur, F., N., Ölmez Bayhan, S., Eren, S., Bayram, Y., 2015. GAP Bölgesi Pamuk Alanlarındaki Bitki Koruma Sorunlarının Belirlenmesi. Türkiye Entomoloji Dergisi, 5(3): 135-146.

Garcia, J.M.B., Garcia, R.O., 1990. Phenology of Heliothis armigera, Agrotis segetum and Agrotis ipsilon in the Badajoz Area (Spain). OILB SROP WPRS Bulletin, 13(3): 1-5.

Göven, M. A., Efil, L., 1994. Dicle Vadisi Pamuk Alanlarında zararlı Yeşilkurt (Heliothis armigera Hübn.) (Lepidoptera: Noctuidae) 'un Doğal düşmanları ve Etkinlikleri Üzerinde Araştırmalar. Türkiye 3. Biyolojik Mücadele Kongresi, İzmir, pp. 449-457.

Karaat, Ş., Göven, M. A., Mart, C., 1986. Güneydoğu Anadolu Bölgesi'nde Pamuk Ekim Alanlarında Yararlı Türlerin Genel Durumları. Türkiye 1. Biyolojik Mücadele Kongresi, Adana, pp. 186-194.

Kaya, K., (2008). Hatay Illinde Önemli Yazlık ve Kışlık Sebze
Alanlarında Bulunan Zararlı Lepidopter Türleri, Populasyon Yoğunlukları ve Parazitoitleri Üzerinde Araştırmalar. Doktora tezi, Çukurova Üniversitesi Fen Bilimleri Enstitüsü, Adana.

Kim, J., Kwon, M., Maharian, R., 2017. Monitoring of Four Major Lepidopteran Pests in Corn Field and Management of the Helicoverpa armigera. Korean Society of Applied Entomology, 54-54.

Öngören, K., Kaya, N., Türkmen Ş., 1977. Ege Bölgesinde Domateslerde Zarar yapan Yeşilkurt (Heliothis armigera Hübner)'un Morfolojisi, Biyolojisi ve Mücadelesi Üzerinde Araştırmalar. Bitki Koruma Bülteni, 17(1): 3-28.

Temiz, M.G., Kurt F., Öztürk, F. 2016. Combining Ability For Yield And Fiber Quality Properties In A $7 \times 7$ HalfDiallel Cotton (Gossypium Ssp.) Population. FEB Fresenius Environmental Bulletin, Vol 25-no:12a p:6120-6123

Tsitsipis, J.A., Alexandri, M., 1990. Monitoring Helicoverpa armigera, Scotia ipsilon and Scotia segetum by Pheromone Traps in Greece, Comparison of Two Kinds of Traps. OILB SROP WPRS Bulletin, 13(3): 5461.

TÜik, 2015. Türkiye İstatistik Kurumu. Erişim: (http://www.biruni.tuik.gov.tr) Erişim Tarihi: 29.05.2016.

Yabaş, M. N., Özer, M., 1983. Çukurova Bölgesinde Helicoverpa armigera (Hübner)'nın bio-ekolojisi üzerinde araştırmalar. Tübitak VII. Bilim Kongresi, Tarım ve Ormancılık Araştırma Grubu Tebliğleri, Adana, 6-10 Ekim 1983. 